\title{
LA DISTINCIÓN SENTIDO-REFERENCIA, Y LA TESIS DE LA IDENTIDAD EN EL MATERIALISMO*
}

El materialismo sostiene que la mente o lo mental es materia. Hay varias formas de especificar esto. Se puede afirmar que lo mental es en realidad o realmente algo material o materia, es decir, que a pesar de las apariencias en contra, lo mental sólo es una forma de lo material o de la materia.

¿Qué materia puede ser la que compone lo mental? Éste resulta un tema de controversia. Unos afirman que la materia sin más, es decir, sin análisis adicional; otros afirman que un órgano del cuerpo humano, por ejemplo, el cerebro; otros más, que la identidad se da entre lo mental y un compuesto neurofisiológico o bioquímico. Otros afirman que la identidad se da con la materia según la determina la ciencia, esto es, según resultará determinada en el avance de la investigación científica.

La tesis materialista siempre ha resultado repugnante frente a hechos cotidianos como nuestra conciencia o el sentimiento de nuestra propia existencia e identidad. Nos parece que nuestro pensamiento, nuestra imaginación, nuestra creatividad y nuestro yo no pueden ser algo material, algo como una piedra o una sustancia química, por sutil que ésta sea. Aunque nos fascine la idea de no ser extraños en el concierto universal, pensamos que esta participación en la totalidad no debe conducir a nuestra aniquilación en la materia, sino que debe preservarse nuestra singularidad como sujetos que piensan y actúan frente a lo material. ¿Qué hacer ante esta actitud? ¿Cómo satisfacer este deseo de singularidad? ¿Cómo poder sostener que "todo es materia"? Los modernos materialistas creen haber hallado una respuesta a este problema, a saber, distinguir entre el sentido de expresiones como "dolor" y "suceso cerebral C" y la referencia de esas expresiones.

Es decir: los materialistas modernos, siguiendo a Frege, se apoyan en la distinción entre el sentido y la referencia de una oración para acomodar a Ia vez nuestra impresión de que nuestros pensamientos, emociones, etcétera, no son materia, y el hecho de que todo sea material o materia. Veamos.

Como se recordará, Frege distingue entre el sentido de una expresión u oración y su referencia. El ejemplo que utiliza es el de "la estrella matutina" . y "la estrella vespertina": las cuales son dos maneras o formas de hablar acerca de un único y mismo planeta, a saber, Venus. Alguien puede entender las frases "estrella matutina" y "estrella vespertina" sin saber que ambas designan un mismo planeta. Esa persona, después de usar esas frases durante toda su vida, puede llegar a conocer un día que con las dos hablaba del mis-

* El presente trabajo forma parte de una investigación más amplia que versa sobre las teorías de la significación y el concepto de persona. En una segunda parte, abordaré el tema del materialismo en conexión con las teorías de la significación. 
mo planeta. Es decir, el uso apropiado y la comprensión de esas frases resulta independiente - por lo menos en parte_ del conocimiento de la realidad a la que se refieren o sobre la cual versan.

Ese importante ejemplo de Frege nos muestra una separación entre nues. tro lenguaje y nuestra comprensión, por una parte, y por otra, la realidad del mundo, esto es, entre cómo hablamos del mundo y cómo es el mundo, entre lenguaje y realidad, comprensión y verdad, sentido y referencia.

Veamos ahora cómo utilizan y cómo quieren utilizar los modernos materialistas la distinción de Frege. Estos materialistas argumentan que así como las personas, por ejemplo, conocían y entendian lo que es un rayo porque veían el relámpago y oían el estruendo (sin saber que un rayo es una descarga eléctrica y, por lo tanto, sin conocer la naturaleza del rayo), así nosotros conocemos lo que es tener un dolor porque sentimos la sensación y nos contorsionamos, gesticulamos y proferimos voces dolidas, pero ignoramos que el dolor es el resultado de un cambio bioquímico o de un suceso neurofisiológico y por lo tanto ignoramos la naturaleza misma del dolor. Tendríamos así:

Esquema 1
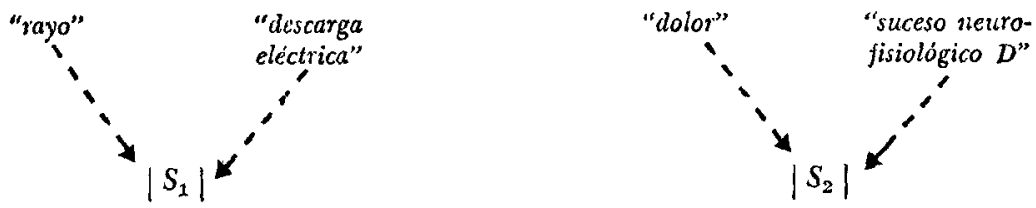

Estos materialistas sostienen, por lo tanto, que con respecto al dolor y a los demás estados mentales estamos en una situación similar a aquella en la que se encontraban las personas con respecto a los rayos, es decir, en ignorancia de otras designaciones alternativas que capturen la naturaleza de los dolores. El uso apropiado del lenguaje del dolor de ninguna manera establece dicha naturaleza. Es verdad que el uso apropiado de "dolor" supone un acceso epistemológico apropiado al dolor. Esto quiere decir, en consecuencia, que no hay un único acceso a la realidad o a la referencia y que, así como podemos acceder al fenómenos atmosférico $S_{1}$ que designamos indistintamente con las denominaciones "rayo" y "descarga eléctrica", asf podemos acceder indistintamente al hecho o ente $S_{2}$ mediante las denominaciones "dolor" o "suceso neurofísiológico $D^{\prime \prime}$.

Por lo tanto, ahora tenemos dos expresiones, dos accesos epistemológicos y un solo hecho o ente. Esto es:

ESQUEMA 2
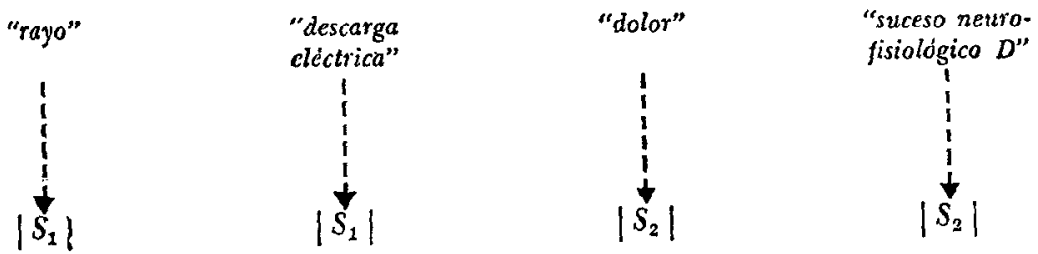
Para evitar confusión debemos eliminar uno de los cuadros. La alternativa que así resulta es la siguiente: dejar un solo cuadro conectado a las líneas punteadas que designan accesos epistemológicos, como en el primer esquema, o bien, introducir el signo de identidad entre los cuadros $S_{1}$ y los cuadros $S_{2}$. De este modo tendriamos:

\section{ESQUEMA 3}

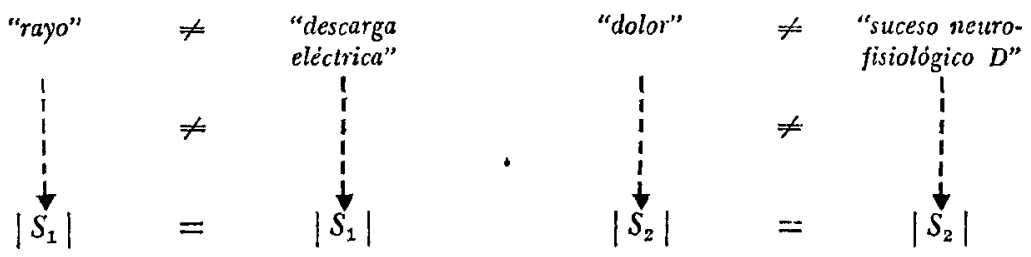

Algunos materialistas modernos hablan aquí de una identidad contingente. Esto no deja de ser extraño, pues el esquema anterior deja en claro que en cada caso, es decir, en $S_{1}$ y $S_{2}$, hay dos designaciones, dos accesos epistemológicos y dos hechos o referentes que resultan ser un solo hecho o referencia. La identidad sólo se establece entre $S_{1}$ y entre $S_{2}$, no entre las expresiones ni entre los accesos epistemológicos.

Esto último resulta de crucial importancia a la vez para lo que estos materialistas dicen y lo que quieren decir. Por una parte, está nuestro problema inicial, a saber, cómo compaginar nuestra intuición de que lo mental es completamente diferente de lo material, con la afirmación de que "todo es materia". La respuesta es directa: la diferencia está en las designaciones y en nuestro acceso epistemológico. La identidad está más allá del lenguaje y del conocimiento. El lenguaje y el conocimiento de "dolor" y de "suceso neurofisiológico $D$ " siempre serán diferentes y podremos estar seguros de que, en este sentido y este nivel, mi dolor no es ni será algo cerebral. Pero esta diferencia no elimina una identidad que, desconocida aún, puede darse en otro nivel y que hace que inconscientemente y en ignorancia me esté refiriendo a un único y mismo suceso o hecho cuando digo "me duele" y cuando digo "ocurre un suceso neurofisiológico $D^{\prime \prime}$.

En esta forma parece que la distinción sentido-referencia puede acomodar lo que parecía incompatible ${ }^{1}$ y satisfacer nuestro provincialismo epistemológico dándonos la tranquilidad de que nuestros dolores, pensamientos, intenciones, etcétera, no se reducen a mera materia sino que son algo más, algo sobre y por encima de la materia. Este "algo más" queda acomodado en el lenguaje y en el acceso epistemológico y deja la puerta abierta para que sin embargo se establezca que el dolor es (idéntico con) un suceso neurofisiológico de un tipo dado.

1 Es decir, acomodar nuestra subjetividad frente al mundo. Nuestra experiencia del dolor queda del lado del sentido, junto con el lenguaje con el que nos expresamos. El dolor mismo queda del lado de la referencia. Este desmantelamiento ha sido puesto en duda recientemente por S. Kripke y T. Nagel. Para Kripke véase la nota 7. Para Nagel véase Mortal Questions (Cambridge U. P., 1979), capitulos 12 y 14. 
Pero algunos materialistas modernos, al elaborar el anterior punto de vista, dicen que la identidad entre los $S_{1}$ y los $S_{2}$ es una identidad contingente. ¿En qué consiste la contingencia de esta identidad?

U. T. Place dice que "la conciencia es un proceso cerebral" 2 y "un enunciado contingente verificado por observación..." Lo que él desea es contrastar ese enunciado con enunciados del tipo "un triángulo es una figura con tres ángulos", que se establecen por definición. Según Place, la identidad entre "conciencia" y "proceso cerebral" se establece mediante dos procesos de verificación: uno, la autobservación; otro, ciertos procesos especiales de observación compleja. ${ }^{3}$ En forma equívoca, Place dice que el proceso para determinar la naturaleza de "conciencia" es radicalmente diferente del proceso para determinar la naturaleza de "proceso cerebral".".

J. C. Smart coincide con Place acerca de la contingencia de la identidad y dice: " 'La estrella matutina y la estrella vespertina son una y la misma cosa' es una proposición contingente." 5 Para Smart, el camino hacia la identidad es más complejo de lo que Place admite, porque implica la introducción de un lenguaje tópico-neutral, pero su adhesión a la tesis de la contingencia de la identidad es irrestricta.

La tesis de la contingencia de la identidad es extraña porque una vez que se ha distinguido entre el nivel lingüístico y el epistemológico, por un lado, y un nivel ontológico por el otro, y se dice abundantemente que nueștro acceso a la identidad es mútliple y diverso, pero que la identidad es única, no parece haber lugar para afirmar ninguna contingencia en ella.

No hay lugar para la contingencia porque la diferencia entre el caso del triángulo y el caso de la conciencia reside precisamente en el modo como se establece o se descubre la identidad, no en nada que concierna a la identidad misma. La contingencia - si la hay o si ésta es la palabra adecuada para conceptuar el hecho en cuestión- ${ }^{6}$ está del lado del acceso epistemológico a la identidad y del lado de su expresión lingüística.

La contingencia está del lado del acceso epistemológico porque los procesos de observación o verificación de "conciencia" y "proceso cerebral" - - , en nuestro ejemplo anterior, "dolor" y "suceso neurofisiológico"- - son diferentes

2 "Is Consciousness a Brain Process?", en ,C. V. Borst (ed.), The Mind/Brain Identity Theory (Macmillan, 1970).

3 Resulta extraño hablar de verificación al fijar la referencia de los términos de la identidad.

4 Place habla de procesos mediante los cuales, y a partir del lenguaje común, vamos - con el auxilio de la ciencia - aproximándonos en forma gradual a la referencia, hasta fijar definitivamente su naturaleza.

5 C. V. Borst, op. cit. Hay que observar que lo que se declara contingente es la proposición, es decir, el lenguaje, pero esto no establece que aquello de lo que habla la proposición - la identidad - tenga que ser contingente. Aqui es donde Smart ignora la fuerza y el motivo de la distinción sentido-referencia y la usa en una dirección opuesta a la que tiene.

6 Kripke ha señalado que hay en esto una confusión entre dos distinciones, a saber, la de a priori-a posteriori y la de necesidad y contingencia. La primera concierne al orden del conocimiento, la segunda al orden de la existencia. Esta forma de ponerlo juega muy bien con la tesis de la distinción sentido-referencia. Cf. nota 7 . 
en cuanto a su naturaleza y en cuanto al tiempo en el que se llevan a cabo. Y está también del lado del lenguaje porque las expresiones "dolor" y "suceso neurofisiológico" - de acuerdo con Place y Smart_ no son, quizá, las adecuadas, y en todo caso se trata de expresiones que no reflejan la unidad de la referencia acerca de la cual hablan. Son expresiones que muestran, por lo tanto, una arbitrariedad frente a la necesidad ontológica que constituye el caso.

Asf́ pues, en la medida en que el acceso epistemológico a la identidad en cuestión no tiene que ser único, y en la medida en que las expresiones que forman los polos de la identidad sugieren una pluralidad engañosa, podemos. aceptar una forma de contingencia en esos niveles, pero no tenemos por qué hacerlo en el nivel de la identidad misma. Es más, precisamente en la medida en que hablamos de contingencia en esos niveles lingüístico y epistemológico, hablamos correlativamente de una instancia que no es contingente ella misma. Así, hablamos de un acceso por el cual arribamos a algo que no tiene el carácter del'acceso, y de una forma lingüística que difiere de aquello a lo cual se refiere.

La distinción sentido-referencia, en la medida en que es una distinción fundamental y auténtica, obliga por lo tanto a poner la contingencia o el carácter a posteriori - para hablar con Kripke - del lado del sentido, y deja aparte el carácter modal de la referencia. Pero este "dejar aparte" sólo quiere decir que los argumentos de Smart y Place no reconocen la fuerza de la distinción entre sentido y referencia con la cual han podido introducir con mayor plausibilidad la tesis materialista, y se han comprometido, sin argumentos, en favor de una contingencia de la identidad. Concomitantemente, la cuestión del carácter modal de la identidad queda a salvo de su interpretación y, aun cuando hay una presunción en favor de su necesidad vis à vis con la contingencia o el carácter a posteriori del sentido, es necesario argumentar explícitamente en favor de esta necesidad.?

Retornemos a lo dicho antes acerca de lo que Smart y Place dicen y lo que quieren decir: lo que dicen es que el acceso a la identidad es múltiple y que la identidad es, por lo tanto, contingente; lo que quieren y pueden decir es que el acceso a la identidad es múltiple y a posteriori y quizá contingente, y que la identidad misma así descubierta se encuentra más allá de ese acceso y por ello no está contagiada de las características que agobian a su acceso.

INSTITUTO DE INVESTIGACIONES FILOSÓFICAS

ENRiQue Villanteva Universidad Nacional Autónoma de México

$7 \mathrm{El}$ argumento más excitante en este sentido es el de Kripke. Véase Identidad y necesidad (Cuadernos de Critica No 5); también Naming \& Necessity, en Harman \& Davidson (eds.), Semantics of National Languages (Reidel), próximamente en Cuadernos de Critica. 